\title{
ASPECTOS BIOLÓGICOS DE Chrysoperla externa (Hagen, 1861) (Neuroptera: Chrysopidae) ALIMENTADA COM Bemisia tabaci (Gennadius, 1889) BIÓTIPO B (Hemiptera: Aleyrodidae) CRIADA EM TRÊS HOSPEDEIROS
}

\author{
Biological aspects of Chrysoperla externa (Hagen, 1861) \\ (Neuroptera: Chrysopidae) fed on Bemisia tabaci (Gennadius, 1889) \\ biotype B (Hemiptera: Aleyrodidae) reared in three hosts
}

\author{
Cláudio Gonçalves Silva ${ }^{1}$, Alexander Machado Auad ${ }^{2}$, Brígida Souza ${ }^{3}$, \\ César Freire Carvalho ${ }^{3}$, Jean Patrick Bonani ${ }^{4}$
}

\begin{abstract}
RESUMO
Estudaram-se alguns aspectos biológicos de adultos de Chrysoperla externa (Hagen) oriundos de larvas alimentadas com ninfas da mosca-branca Bemisia tabaci (Gennadius) biótipo B, criadas em folhas de pepino (Cucumis sativus) var. caipira, couve (Brassica oleraceae) var. acephala e na planta invasora leiteiro (Euphorbia heterophylla). Discos foliares dos hospedeiros contendo ninfas de terceiro e quarto estádios da mosca-branca foram acondicionados em placas de Petri contendo ágar-água a $1 \%$. Em cada placa foi colocada uma larva de $C$. externa recém-eclodida, onde permaneceram até a emergência dos adultos. Foram avaliados o peso logo após a emergência, os períodos de pré-oviposição, oviposição, efetivo de oviposição, pós-oviposição, número total de ovos produzidos por fêmea e longevidade. Avaliaram-se, também, o período embrionário e a viabilidade dos ovos, coletando-se, uma vez por semana, uma amostra de $10 \%$ do total de ovos produzidos no dia, ao longo de todo o período reprodutivo. O peso de machos e fêmeas não diferiu significativamente em função do hospedeiro da presa, sendo em média de 4,7 mg. De maneira geral, adultos de C. externa oriundos de larvas alimentadas com ninfas de B. tabaci biótipo B criadas em leiteiro apresentaram performance inferior em relação àqueles oriundos do pepino e da couve. O período de oviposição foi, em média, de 49,5 dias para o pepino e a couve, e de 31,6 dias para o leiteiro. A produção de ovos foi reduzida em aproximadamente 50\% em leiteiro, sendo de 293,8 ovos; no pepino e couve, a média foi de 591,3 ovos. Ninfas de B. tabaci biótipo B criadas em leiteiro causaram uma redução da viabilidade dos ovos de $C$. externa, que foi $62,8 \%$ e $57,7 \%$ inferior ao verificado para o pepino e a couve, respectivamente.
\end{abstract}

Termos para indexação: Crisopídeo, mosca-branca, biologia

\section{ABSTRACT}

The aim was to study some biological aspects of adults of Chrysoperla externa (Hagen), from larvae fed on nymphs of third and fourth stages of Bemisia tabaci (Gennadius) biotype B, and reared on leaves of cucumber (Cucumis sativus), kale (Brassica oleracea) and wild poinsettia (Euphorbia heterophylla). Leaf discs from the hosts containing third and fourth stage nymphs of whitefly, were placed in Petri dishes containing $1 \%$ agar. One recently hatched larvae of C. externa was placed in each dish, until adult emergence. The weight after emergence,eoviposition, oviposition, effective oviposition and postoviposition periods, the total number of eggs per female and longevity were evaluated. The embryonic period and the survival rate of the eggs were also recorded by collecting weekly samples of $10 \%$ of the daily egg production, throughout the reproductive period. The weights of males and females did not differ in relation to the hosts, the average being $4.7 \mathrm{mg}$. In general, adults of $C$. externa, coming from larvae fed on B. tabaci biotype B nymphs reared on leaves of the host wild poinsettia, had their biological characters affected, in comparison with those on leaves of cucumber and kale. The oviposition period averaged 49.5 days for cucumber and kale, and 31.6 days for wild poinsettia. Egg laying capacity was reduced by $50 \%$ on wild poinsettia, its being 293.8 eggs. In cucumber and kale, the average was 591.3 eggs. Nymphs of $B$. tabaci biotype B reared on wild poinsettia caused increase of the embrionic period and a reduction of the survival rate of the eggs, its being $62.8 \%$ and $57.7 \%$ lower than that presented by the ones reared on cucumber and kale, respectively.

Index terms: Green lacewing, whitefly, biology.

(Recebido para publicação em 16 de abril de 2003 e aprovado em 15 de outubro de 2003)

\footnotetext{
1. Biólogo, Doutorando, Departamento de Entomologia, Universidade Federal de Lavras/UFLA, Caixa Postal 37, 37200-000, Lavras, MG. ziwky@yahoo.com.br.

2. Engenheiro Agrônomo, Pesquisador da Embrapa Gado de Leite, Juiz de Fora, MG.

3. Professores do Departamento de Entomologia/UFLA

4. Engenheiro Agrônomo, Mestrando em Entomologia, UFLA.
} 


\section{INTRODUÇÃO}

As espécies de mosca-branca mais importantes para a economia mundial são Bemisia tabaci (Gennadius, 1889) e Bemisia argentifolii (BELLOWS \& PERRING, 1994) (Hemiptera: Aleyrodidae), essa última também conhecida como Bemisia tabaci biótipo B. Esses insetos reproduzem-se em mais de 600 hospedeiros, sendo comumente encontrados em culturas de alto valor econômico, plantas ornamentais e invasoras, transmitindo vírus pertencentes às famílias Geminiviridae e Closteroviridae (FLINT, 1995; OLIVEIRA et al., 2001). Os prejuízos causados por $B$. tabaci biótipo B são significativos e seu controle é objeto de estudo por diversos pesquisadores em todas as partes do mundo onde sua presença é detectada (OLIVEIRA et al., 2001).

Para seu controle, alguns produtos fitossanitários, como os organofosforados e os piretróides, não têm surtido o efeito esperado, pois seu ciclo biológico varia muito em relação ao hospedeiro em que é criado, podendo ter, em curtos períodos, novas gerações, o que confere a esse inseto alto potencial de resistência. Além disso, produtos não-seletivos afetam negativamente os inimigos naturais (FLINT, 1995; PALUMBO et al., 2001).

O controle biológico vem assumindo grande importância na redução da densidade populacional de moscas-brancas. São utilizados com sucesso parasitóides dos gêneros Eretmocerus e Encarsia (Hymenoptera: Aphelinidae), os predadores Delphastus pusillus (LeConte, 1852) (Coleoptera: Coccinellidae) e Chrysoperla sp. (Neuroptera: Chrysopidae), patógenos (protozoários, fungos, nematóides entomopatogênicos) e outros organismos (LENTEREN e MARTIN, 1999).

A eficiência do agente de controle empregado para o controle biológico está relacionada, em grande parte, com a qualidade do hospedeiro em que a praga se encontra. Algumas estruturas utilizadas para proteção da planta, como os tricomas, por exemplo, podem afetar o pouso, caminhamento e/ou oviposição do inimigo natural. A produção de alguns compostos químicos que podem ser sintetizados pela praga pode influenciar negativamente o ciclo biológico do inimigo natural (McAUSLANE, 1996).

Entre os agentes utilizados em programas de controle biológico de mosca-branca, os crisopídeos têm sido encontrados em vários agroecossistemas alimentando-se de ovos e ninfas dessa praga, exercendo, assim, o controle biológico natural. Experimentos em laboratório têm evidenciado a potencialidade desses predadores na redução da densidade populacional de mos- cas-brancas (AUAD et al., 2001, 2002), o que viabiliza a sua utilização em programas de Manejo Integrado de Pragas.

Objetivou-se com este trabalho estudar a performance de adultos de Chrysoperla externa (Hagen, 1861), uma espécie de ocorrência comum na Região Neotropical, provenientes de larvas alimentadas com ninfas de $B$. tabaci biótipo $\mathrm{B}$, criadas em três hospedeiros.

\section{MATERIAL E MÉTODOS}

As larvas dos crisopídeos foram provenientes de ovos da criação de manutenção do Laboratório de Biologia de Insetos da Universidade Federal de Lavras (UFLA), MG, onde são mantidos em sala climatizada a $25^{\circ} \mathrm{C}$, UR de $70 \%$ e fotofase de 12 horas e alimentados com uma dieta à base de levedura de cerveja e mel (1:1). Os ovos foram coletados com até 24 horas de idade e individualizados em placas de microtitulação utilizadas em teste ELISA (enzime linked immunosorbent assay). As placas foram vedadas com filme de PVC laminado e mantidas em câmaras climatizadas ajustadas para as mesmas condições da criação de laboratório, onde permaneceram até a eclosão.

Sementes de tomate variedade Santa Clara foram plantadas em compartimentos de isopor contendo o substrato Plantmax ${ }^{\circledR}$. Após a germinação, foi feito o transplantio para vasos de PVC com capacidade para 2 $\mathrm{kg}$, contendo uma mistura de solo e matéria orgânica adubada com a formulação NPK 4-14-8. Com cerca de 30 dias de idade, as plantas foram infestadas com adultos de B. tabaci biótipo B, para a multiplicação do aleirodídeo. Os vasos foram mantidos em casa-devegetação sobre uma bancada de $1,0 \mathrm{~m}$ de altura x 1,0 $\mathrm{m}$ de largura $\mathrm{x}$ 2,0 $\mathrm{m}$ de comprimento e repostos à medida que as plantas entravam no período de senescência.

Para os bioensaios, foram utilizados como hospedeiros de B. tabaci biótipo $\mathrm{B}$, o pepino [Cucumis sativus (L.)] var. caipira que, entre as culturas oleráceas tropicais, possui ampla aceitação popular, e a couvemanteiga [Brassica oleracea (L.)] var. acephala, a qual ocupa um lugar proeminente na olericultura do CentroSul do Brasil (FILGUEIRA, 1987; RESENDE e FLORI, 2003). Utilizou-se também a planta invasora leiteiro [Euphorbia heterophylla (L.)], que é frequiente em todo o País, ocorrendo em culturas anuais e perenes (LORENZI, 1982).

As plantas foram cultivadas em vasos de PVC com capacidade para $2 \mathrm{~kg}$, em substrato composto por solo e esterco de bovino (1:1), adubadas com a formulação NPK 4-14-8 e mantidos em casa-de-vegetação até completarem 30 dias de idade. Nessa ocasião, grupos de

Ciênc. agrotec., Lavras, v. 28, n. 2, p. 243-250, mar./abr., 2004 
três vasos de cada hospedeiro, num total de 39 de cada um deles, foram retirados diariamente e colocados juntos à criação de manutenção de mosca-branca, visando à sua infestação, onde permaneceram por 48 horas. $\mathrm{O}$ escalonamento das infestações das plantas hospedeiras foi utilizado para que se obtivessem ninfas de terceiro e quarto estádios em número suficiente para alimentação do predador, ao longo de todo o período de desenvolvimento larval.

Larvas de $C$. externa recém-eclodidas foram acondicionadas em placas de Petri de $5 \mathrm{~cm}$ de diâmetro contendo discos foliares da planta hospedeira, infestados por ninfas de terceiro e quarto estádios da praga, em número suficiente para que as larvas pudessem alimentar-se "ad libitum". Os recipientes com os insetos nas fases pré-imaginais permaneceram em câmaras climatizadas reguladas a $25 \pm 1{ }^{\circ} \mathrm{C}$, UR de $70 \pm 10 \%$ e fotofase de 12 horas. Após a emergência e eliminação do mecônio, os adultos foram pesados e separados por sexo utilizando-se microscópio estereoscópico para observação da genitália externa. Procedeu-se à formação de casais, os quais foram mantidos em gaiolas de $\mathrm{PVC}$ de $10 \mathrm{~cm}$ de altura x $10 \mathrm{~cm}$ de diâmetro, seguindo-se a metodologia desenvolvida por Ribeiro (1988). Os insetos foram acondicionados em sala climatizada nas mesmas condições nas quais desenvolveram-se as fases imaturas.

Foram avaliados o peso, os períodos de préoviposição, oviposição, efetivo de oviposição, pósoviposição, número total de ovos produzidos por fêmea e longevidade. Avaliaram-se também o período embrionário e a viabilidade dos ovos, coletando-se, uma vez por semana, uma amostra de $10 \%$ do total de ovos produzidos no dia, ao longo de todo período reprodutivo e individualizando-os em placas de microtitulação utilizadas em teste ELISA. Efetuou-se a análise de variância seguida de teste de médias de Scott \& Knott a 5\% de probabilidade.

\section{RESULTADOS E DISCUSSÃO}

\section{Peso}

Não foram verificadas diferenças significativas no peso de adultos de $C$. externa em função do hospedeiro utilizado na criação de ninfas de moscas-brancas fornecidas às larvas desse predador (Figura 1). Os resul- tados obtidos foram inferiores àqueles encontrados por Figueira (2001), que constatou um peso médio de 5,7 mg para adultos de C. externa oriundos de larvas alimentadas com ninfas do pulgão Schizaphis graminum (Rondani, 1852) criado na cultivar BR 0078 de sorgo.

\section{Aspectos reprodutivos}

O período de pré-oviposição não diferiu significativamente em função do hospedeiro onde as ninfas de B. tabaci biótipo B foram criadas. Porém, apresentou maior duração em relação aos resultados obtidos por Ribeiro (1988), que constatou 3,2 e 4,2 dias para fêmeas oriundas de larvas alimentadas com ovos de $A$ nagasta kuehniella (Zeller, 1879) (Lepidoptera: Pyralidae) e Alabama argillacea (Hübner, 1818) (Lepidoptera: Noctuidae), respectivamente. Os períodos de oviposição, efetivo de oviposição e o número de ovos produzidos foram influenciados pelo tipo de alimento das ninfas de mosca-branca, observando-se, em folhas de leiteiro, uma redução da ordem de $50 \%$ no número de ovos/fêmea.

Provavelmente, a presença de alguma substância produzida pela planta leiteiro é transferida ao predador por meio da ingestão da presa, afetando a sua atividade reprodutiva, concordando com os registros de Havill e Haffa (2000) para parasitóides de um modo geral. Nesse hospedeiro, é conhecida a presença de uma substância com alta toxicidade denominada lacto-resina (FLORA MEDICINAL, 2003), que pode ter afetado o predador, pois sabe-se que alguns insetos fitófagos conseguem metabolizar compostos secundários a seu favor, prejudicando o inimigo natural (LEGASPI et al., 1996; McAUSLANE, 1996). O período de pós-oviposição teve maior duração para fêmeas oriundas de larvas alimentadas com ninfas criadas em folhas de pepino (Tabela 1$)$.

Os resultados diferiram daqueles encontrados por Auad et al. (2002), quando ofereceram às larvas de $C$. externa ninfas de B. tabaci biótipo B criadas em folhas de tomateiro, obtendo uma duração de $5,1 \pm 0,21$; $56,8 \pm 1,62$ e $51,4 \pm 2,12$ dias para os períodos de pré-oviposição, oviposição e efetivo de oviposição, respectivamente, e uma produção total de 711,8 \pm 10,57 ovos. 


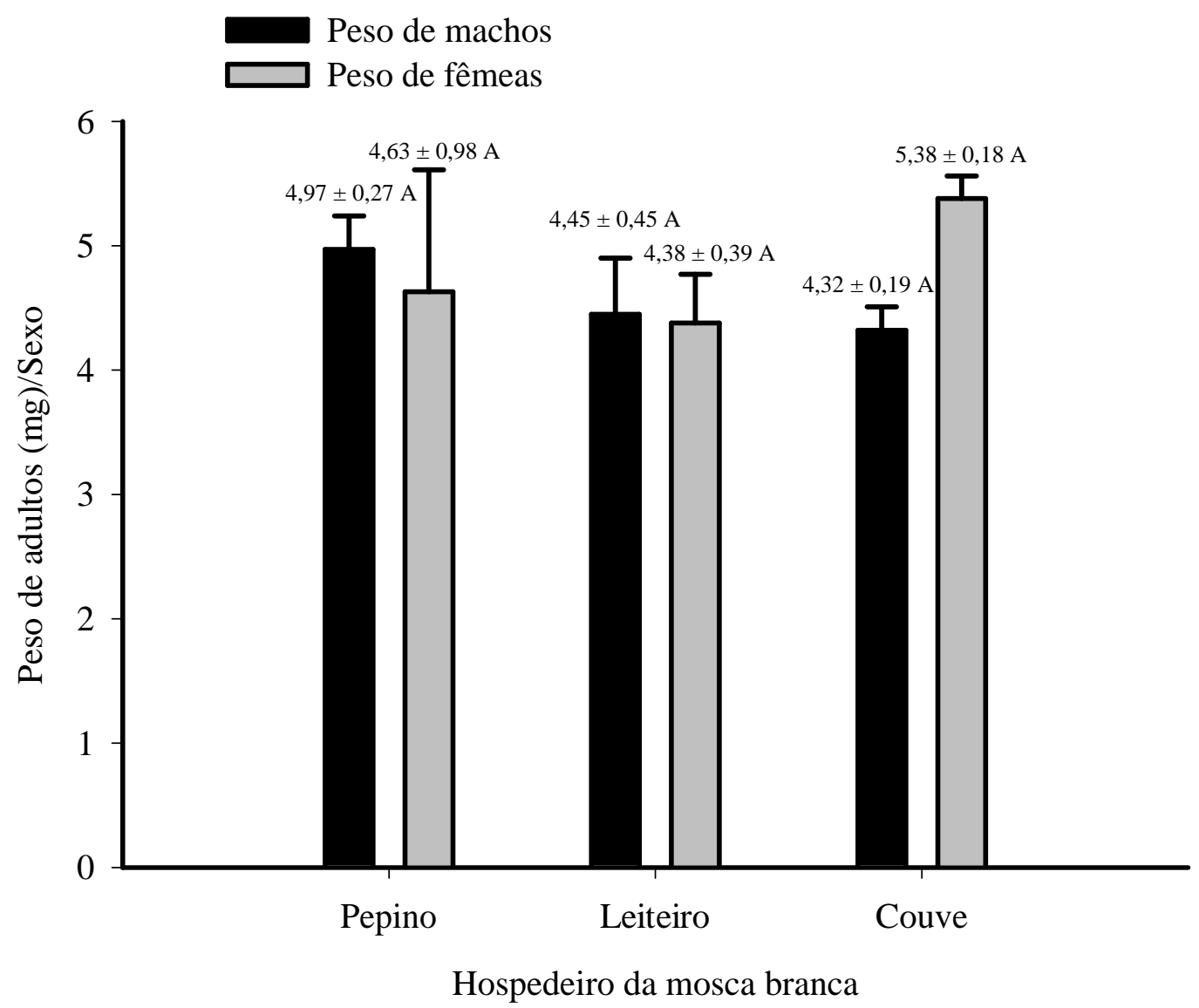

FIGURA 1 - Peso (mg) ( \pm EP) de adultos machos e fêmeas de Chrysoperla externa com até 24 horas de idade, cujas larvas foram alimentadas com ninfas de Bemisia tabaci biótipo B criadas em três hospedeiros. Temperatura $25 \pm$ $1^{\circ} \mathrm{C}$, UR $70 \pm 10 \%$; fotofase 12 horas. Médias seguidas pela mesma letra não diferem entre si pelo teste de Scott \& $\operatorname{Knott}(\mathrm{P}<0,05)$.

A produção total de ovos por fêmeas provenientes de larvas alimentadas com ninfas criadas em folhas de qualquer um dos três hospedeiros estudados foi inferior àquela constatada por Angelini et al. (2002), quando forneceram ovos de Sitotroga cerealella (Olivier, 1789) (Lepidoptera: Gelechiidae) às larvas de C. externa, observando-se uma produção de 667,5 ovos. Os resultados obtidos, independentemente do hospedeiro da praga, também foram inferiores àqueles verificados por Ribeiro et al. (1991), para larvas alimentadas com ovos de A. kuehniella, reiterando as constatações de que al- gum fator inerente à planta hospedeira de B. tabaci biótipo B interferiu na performance do predador.

\section{Longevidade}

Ninfas de B. tabaci biótipo B criadas em folhas de leiteiro e fornecidas às larvas acarretaram uma redução próxima a $30 \%$ e $50 \%$ na duração da fase adulta do crisopídeo, em relação àquelas criadas em pepino e couve, respectivamente (Figura 2). 
TABELA 1 - Características reprodutivas $( \pm \mathrm{EP})$ de fêmeas de Chrysoperla externa, cujas larvas foram alimentadas com ninfas de Bemisia tabaci biótipo B criadas em três hospedeiros. Temperatura $25 \pm 1^{\circ} \mathrm{C}$, UR $70 \pm 10 \%$; fotofase 12 horas.

\begin{tabular}{|c|c|c|c|c|c|c|}
\hline \multirow[b]{2}{*}{ Hospedeiros } & \multirow{2}{*}{$\begin{array}{l}\text { Número } \\
\text { de casais }\end{array}$} & \multicolumn{4}{|c|}{ Períodos } & \multirow{2}{*}{ Ovos/fêmea } \\
\hline & & $\begin{array}{c}\text { Pré- } \\
\text { oviposição }\end{array}$ & Oviposição & $\begin{array}{l}\text { Efetivo de } \\
\text { oviposição }\end{array}$ & Pós-oviposição & \\
\hline Pepino & 12 & $6,08 \pm 0,18 \mathrm{~A}$ & $44,42 \pm 3,69 \mathrm{~A}$ & $42,58 \pm 3,79 \mathrm{~A}$ & $8,79 \pm 4,49 \mathrm{~A}$ & $592,08 \pm 62,96 \mathrm{~A}$ \\
\hline Leiteiro & 12 & $8,42 \pm 1,30 \mathrm{~A}$ & $31,58 \pm 8,26 \mathrm{~B}$ & $25,08 \pm 6,73 \mathrm{~B}$ & $2,67 \pm 0,60 \mathrm{~B}$ & $293,83 \pm 97,08 \mathrm{~B}$ \\
\hline Couve & 14 & $8,07 \pm 0,07 \mathrm{~A}$ & $54,57 \pm 3,97 \mathrm{~A}$ & $50,93 \pm 4,54 \mathrm{~A}$ & $1,00 \pm 0,28 \mathrm{~B}$ & $590,50 \pm 62,49 \mathrm{~A}$ \\
\hline $\mathrm{CV}(\%)$ & & 20,71 & 35,82 & 36,64 & 71,91 & 40,01 \\
\hline
\end{tabular}

Médias seguidas pela mesma letra, nas colunas, não diferem entre si pelo teste de Scott \& Knott $(\mathbf{P}<0,05)$.

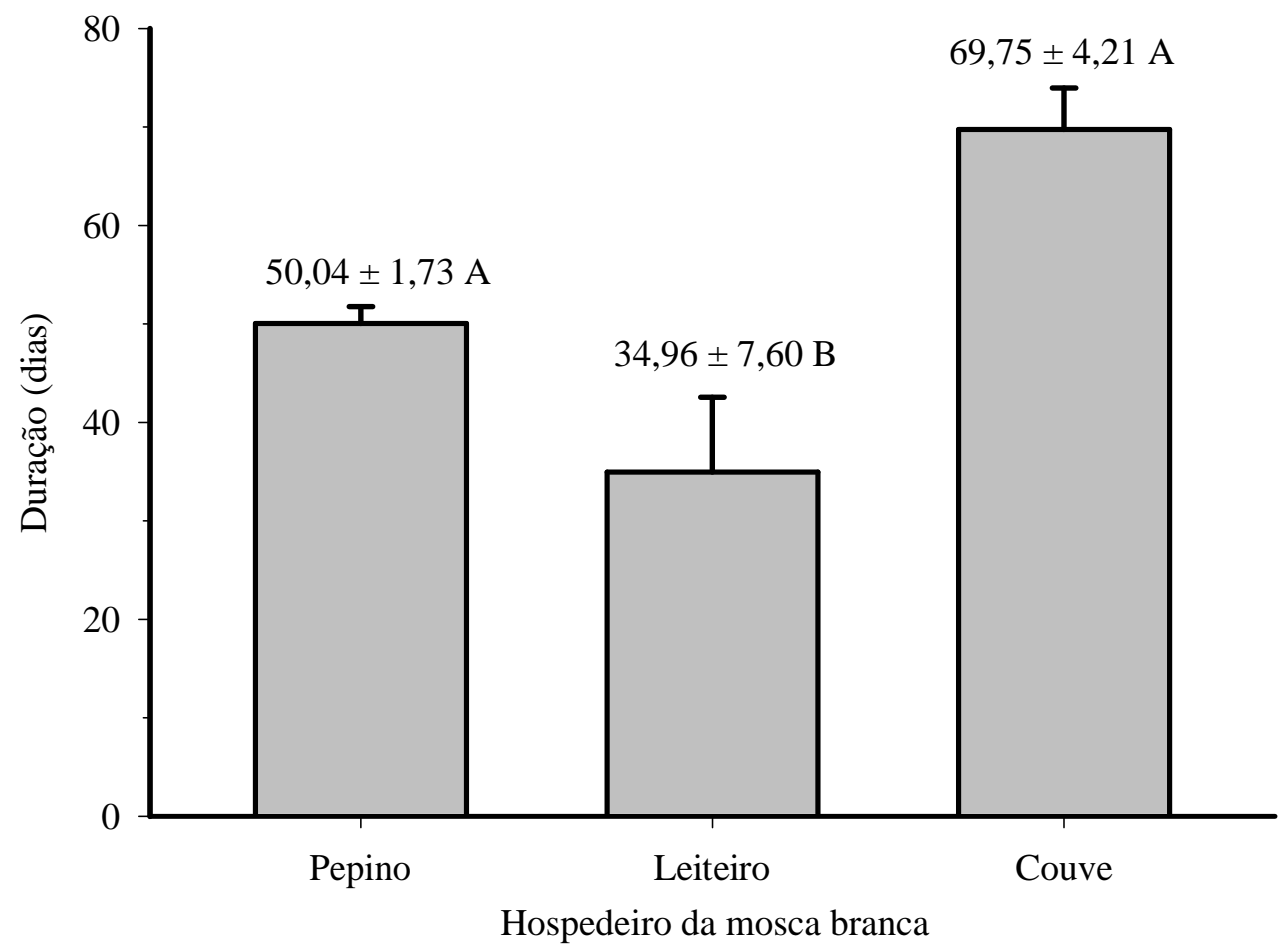

FIGURA 2 - Longevidade ( \pm EP) de Chrysoperla externa, cujas larvas foram alimentadas com ninfas de Bemisia tabaci biótipo B criadas em três hospedeiros. Temperatura $25 \pm 1^{\circ} \mathrm{C}$, UR $70 \pm 10 \%$; fotofase 12 horas. Médias seguidas pela mesma letra não diferem entre si pelo teste de $\operatorname{Scott} \& \operatorname{Knott}(\mathrm{P}<0,05)$. 
A longevidade de adultos provenientes de larvas alimentadas com ninfas criadas em folhas de pepino foi semelhante àquela obtida por Macedo (2001), para larvas supridas com ovos de A. kuehniella. Porém, foi inferior à constatada por Ribeiro et al. (1991), que obtiveram uma longevidade média de 83,2 dias, quando larvas dessa mesma espécie de crisopídeo foram alimentadas com ovos daquele piralídeo. Boregas et al. (2003) observaram que o alimento ingerido pelas larvas de C. externa não afetou a longevidade dos adultos, obtendo uma duração média de 80 dias para machos e de 86 dias para fêmeas, quando alimentados com ovos daquele lepidóptero.

\section{Período embrionário e viabilidade dos ovos}

Em adultos provenientes de larvas alimentadas com ninfas de B. tabaci biótipo B criadas em folhas de pepino, o período embrionário foi mais curto em relação àqueles obtidos para folhas de couve e leiteiro (Figura 3), evidenciando maior adequação da planta de pepino ao crisopídeo. Toscano et al. (2003) obser- varam uma duração de 4,0 dias para essa mesma espécie de predador alimentado com ninfas de moscabranca criadas em folhas de tomateiro.

Fêmeas provenientes de larvas alimentadas com ninfas de mosca-branca oriundas de folhas de leiteiro produziram ovos com menor viabilidade em relação às demais (Figura 4). Esses resultados assemelham-se aos obtidos por Ribeiro (1988), que verificou menor porcentual de ovos viáveis relacionados a presas nutricionalmente inadequadas fornecidas a larvas de C. externa. As viabilidades obtidas para adultos oriundos de larvas criadas em folhas de pepino e couve aproximaram-se daquelas constatadas por Ribeiro et al. (1991), para esse crisopídeo alimentado na fase larval com ovos de $\mathrm{A}$. $\mathrm{ku}$ ehniella.

As comparações com resultados obtidos para adultos de $C$. externa oriundos de larvas alimentadas com ovos de A. kuehniella ou $S$. cerealella foram feitas por se tratarem de presas comumente utilizadas em criações de crisopídeos em laboratório e, portanto, consideradas adequadas ao desenvolvimento desses insetos.

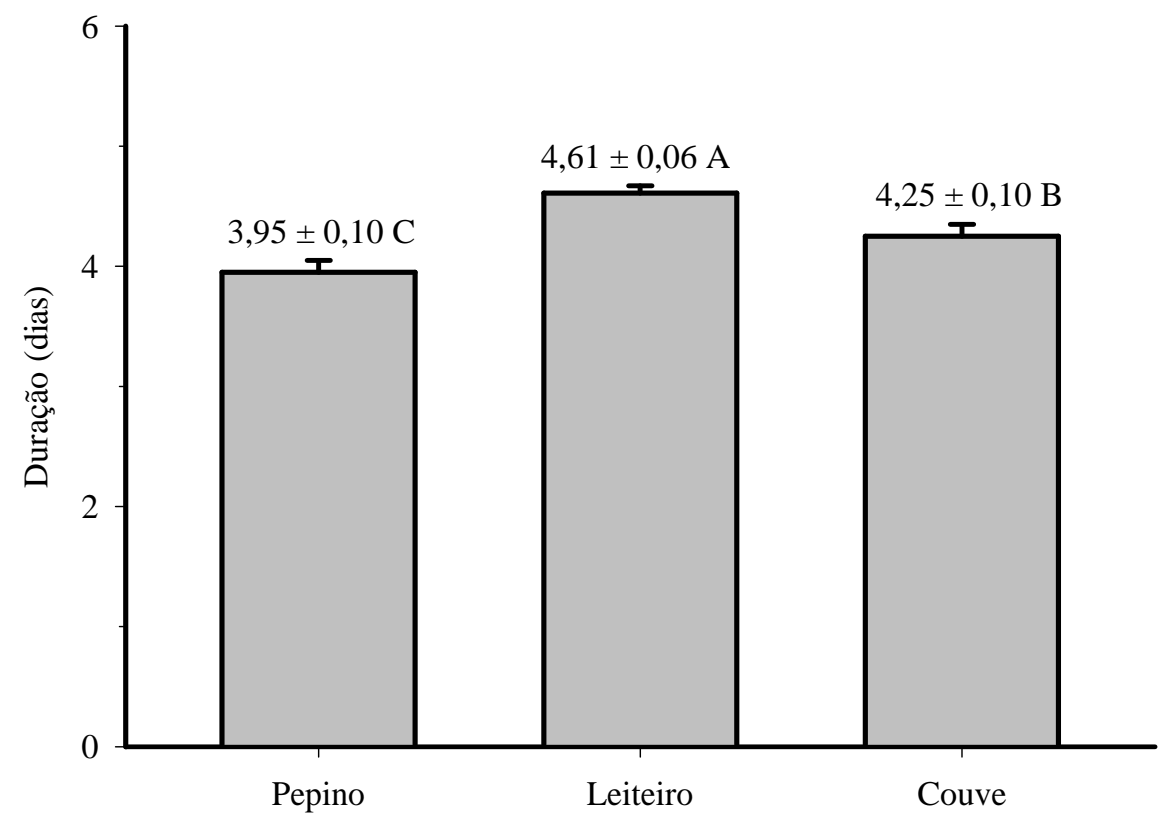

Hospedeiro da mosca branca

FIGURA 3 - Duração ( \pm EP) do período embrionário de Chrysoperla externa, cujas larvas foram alimentadas com ninfas de Bemisia tabaci biótipo B criadas em três hospedeiros. Temperatura $25 \pm 1^{\circ} \mathrm{C}$, UR $70 \pm 10 \%$; fotofase 12 horas. Médias seguidas pela mesma letra não diferem entre si pelo teste de Scott \& Knott $(\mathrm{P}<0,05)$. 


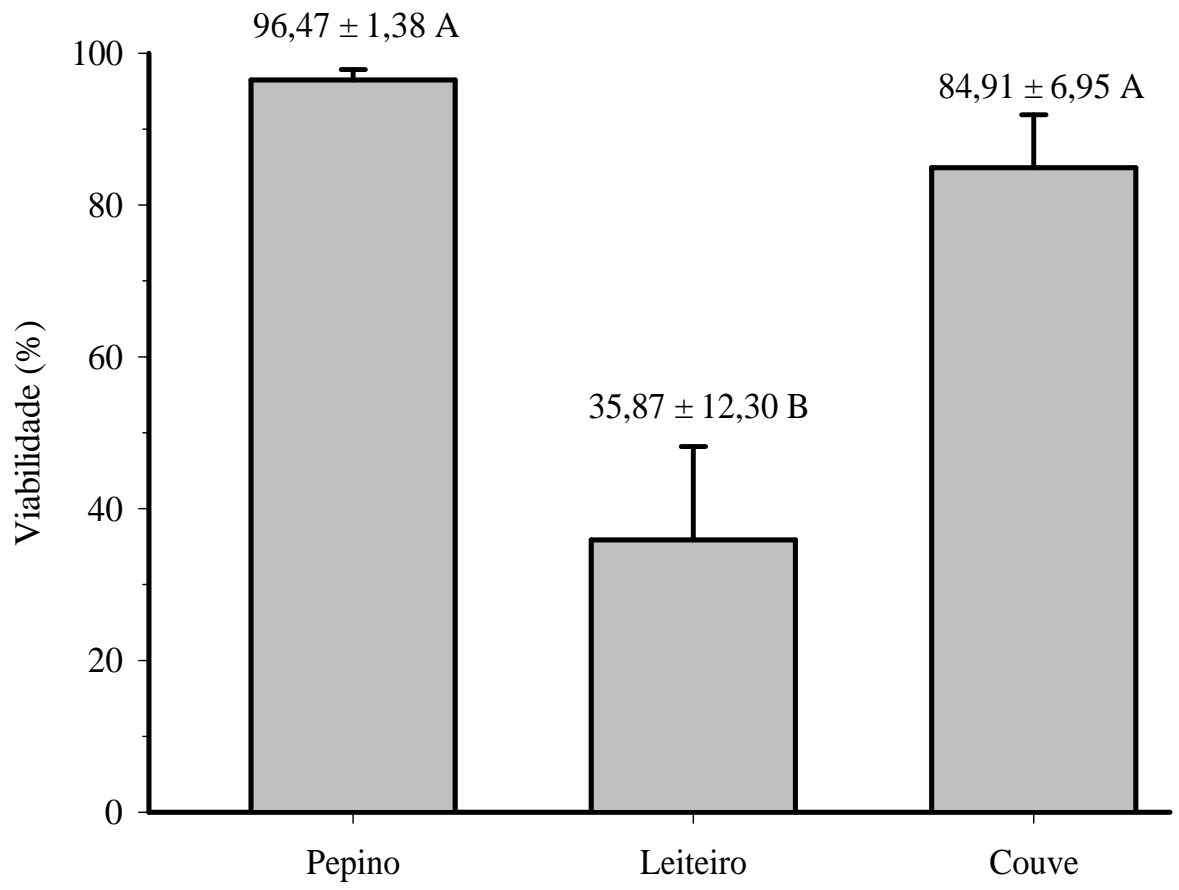

Hospedeiro da mosca branca

FIGURA 4 - Viabilidade ( \pm EP) dos ovos de Chrysoperla externa, cujas larvas foram alimentadas com ninfas de Bemisia tabaci biótipo B criadas em três hospedeiros. Temperatura: $25 \pm 1{ }^{\circ} \mathrm{C}$, UR $70 \pm 10 \%$; fotofase 12 horas. Médias seguidas pela mesma letra não diferem entre si pelo teste de $\operatorname{Scott} \& \operatorname{Knott}(\mathrm{P}<0,05)$.

\section{CONCLUSÃO}

O tipo de planta empregada como hospedeiro de Bemisia tabaci biótipo B e cujas ninfas foram fornecidas como alimento para as larvas de Chrysoperla externa afetou as características biológicas dos adultos desse predador.

\section{REFERÊNCIAS BIBLIOGRÁFICAS}

ANGELINI, M. R.; FREITAS, S.; FREITAS, P. O. Efeito do regime alimentar no desenvolvimento pósembrionário e potencial reprodutivo de Chrysoperla externa (Hagen, 1861) (Neuroptera: Chrysopidae). In: CONGRESSO BRASILEIRO DE ENTOMOLOGIA, 19., 2002, Manaus. Anais... Manaus: INPA, 2002. p. 46.

AUAD, A. M.; CARVALHO, C. F.; SOUZA, B.; GAMA, A. T.; BARBOSA, L. R. Resposta funcional de Chrysoperla externa (Hagen, 1861) (Neuroptera: Chry- sopidae) alimentada com ninfas de Bemisia tabaci biótipo B (Bellows \& Perring) (Hemiptera: Aleyrodidae). In: CONGRESSO BRASILEIRO DE ENTOMOLOGIA, 19., 2002, Manaus. Anais... Manaus: INPA, 2002. p. 47.

AUAD, A. M.; TOSCANO, L. C.; BOIÇA JÚNIOR, A. L.; FREITAS, S. Aspectos biológicos dos estádios imaturos de Chrysoperla externa (Hagen) e Ceraeochrysa cincta (Schneider) (Neuroptera: Chrysopidae) alimentados com ovos e ninfas de Bemisia tabaci (Gennadius) biótipo B (Hemiptera: Aleyrodidae). Neotropical Entomology, Londrina, v. 30, n. 3, p. 429-432, 2001.

BOREGAS, K. G. B.; CARVALHO, C. F.; SOUZA, B. Aspectos biológicos de Chrysoperla externa (Hagen, 1861) (Neuroptera: Chrysopidae) em casa de vegetação. Ciência e Agrotecnologia, Lavras, v. 27, n. 1, p. 7-16, 2003. 
FIGUEIRA, L. K. Controle integrado do pulgãoverde Schizaphis graminum (Rondani, 1852) (Hemiptera: Aphididae) utilizando genótipos de sorgo resistentes e o predador Chrysoperla externa (Hagen, 1861) (Neuroptera: Chrysopidae). 2001. 71 f. Tese (Doutorado em Agronomia. Entomologia Agrícola) Faculdade de Ciências Agrárias e Veterinárias, Jaboticabal, 2001.

FILGUEIRA, F. A. R. ABC da olericultura: guia da pequena horta. São Paulo: Agronômica Ceres, 1987. 164 p.

FLINT, M. L. Whiteflies in California: a resource for cooperative extension. California: UC IPM, 1995. 53 p.

FLORA MEDICINAL. Pesquisa de plantas. Disponível em: «http://www.floramedicinal.com.br>.' Acesso em: 10 jan. 2003.

HAVILL, N. P.; HAFFA, K. F. Compound effects of induced plant responses on insect herbivores and parasitoids: implications for tritrophic interactions. Ecological Entomology, London, v. 25, p. 171-179, 2000.

LEGASPI, J. C.; NORDLUND, D. A.; LEGASPI JÚNIOR, B. C. Tri-trophic interactions and predation rates in Chrysoperla spp. attacking the silverleaf whitefly. Southwestern Entomologist, Weslaco, v. 21, n. 1, p. 33-42, 1996.

LENTEREN, J. C. van; MARTIN, N. A. Biological control of whitefly. In: ALBAJES, R.; GULLINO, M. L.; LENTEREN, J. C. van; ELAD, Y. (Eds.). Integrated pest and disease management in greenhouse crops. Netherlands: [s.n.], 1999. p. 202-216.

LORENZI, H. Plantas daninhas do Brasil. São Paulo: Nova Odessa, 1982. 425 p.

MACEDO, L. P. M. Desenvolvimento, reprodução e comportamento de Chrysoperla externa (Hagen, 1861) (Neuroptera: Chrysopidae) em diferentes con- dições ambientais. 2001. 78 p. Dissertação (Mestrado em Agronomia/Entomologia) - Universidade Federal de Lavras, Lavras, 2001.

McAUSLANE, H. J. Influence of leaf pubescence on ovipositional preference of Bemisia tabaci biótipo B (Homoptera: Aleyrodidae) on soybean. Annals of the Entomological Society of America, College Park, v. 25, n. 4, p. 834-841, 1996.

OLIVEIRA, M. R. V.; HENNEBERRY, T. J.; ANDERSON, P. History, current status, and collaborative research projects for Bemisia tabaci. Crop Protection, Guildford, v. 20, p. 709-723, 2001

PALUMBO, J. C.; HOROWITZ, A. R.; PRABHAKER, $\mathrm{N}$. Insecticidal control and resistence management for Bemisia tabaci. Crop Protection, Guildford, v. 20, p. 739-765, 2001

RESENDE, G. M.; FLORI, J. E. Produtividade de pepino para processamento no Vale do São Francisco. Pesquisa Agropecuária Brasileira, Brasília, v. 38, n. 2, p. 251-255, 2003.

RIBEIRO, M. J. Biologia de Chrysoperla externa (Hagen, 1861) (Neuroptera: Chrysopidae) alimentada com diferentes dietas. 1988. 131 f. Dissertação (Mestrado em Agronomia. Entomologia) - Escola Superior de Agricultura de Lavras, Lavras, 1988.

RIBEIRO, M. J.; CARVALHO, C. F.; MATIOLI, J. C. Influência da alimentação larval sobre a biologia de adultos de Chrysoperla externa (Hagen, 1861) (Neuroptera: Chrysopidae). Ciência e Prática, Lavras, v. 15, n. 4, p. 349-354, 1991.

TOSCANO, L. C.; AUAD, A. M.; FIGUEIRA, L. K. Comportamento de Chrysoperla externa (Hagen, 1861) em genótipos de tomateiro infestados com ovos de Bemisia tabaci (Gennadius, 1889) biótipo B em laboratório. Arquivos do Instituto Biológico, São Paulo, v. 70, n. 1, p. 117-121, 2003. 